\title{
Labor Editorial en Revista Chilena de Radiología vigésimo volumen y proyección al futuro
}

\section{Dr. Claudio Silva F-A.}

Médico radiólogo, Departamento de Imágenes. Facultad de Medicina Clínica Alemana-Universidad del Desarrollo. Santiago-Chile.

La Revista Chilena de Radiología se inició el año 1995, cuando se emitió el número 1, durante la presidencia de SOCHRADI del Dr. Francisco Medina(1). Su primer editor fue el Dr. Pablo Soffia S, y contaba en su Comité Editorial con el Dr. Enrique Bosch O, Dr. Jorge Cervilla O, Dr. Cristián García B. y Dra. Pilar Orellana B. La Revista nace para cumplir un rol muy deseado por la comunidad radiológica nacional, cual era dar difusión y educación continua para toda los radiólogos y residentes de radiología.

Destacable es la labor cumplida por el Dr. José Domingo Arce, quien tuvo la tarea de Editor durante los años 2001-2006, contribuyendo enormemente a estructurar y dar una continuidad funcional que es operativa hasta el día de hoy. Durante su gestión se logró su inclusión en Scielo, lo que marcó el inicio de la internacionalización de nuestra Revista.

También quisiera resaltar la labor cumplida por la Dra. Karla Moënne, quien proyectó nuestra Revista con ímpetu y fuerza, extendiendo nuestro ámbito de acción a la Revista Virtual del Colegio Interamericano de Radiología, donde participó desde su origen.

Actualmente, aparte de la presencia que tenemos en SciElo (y por esta vía en BIREME), artículos seleccionados de nuestra Revista son traducidos al inglés y difundidos a través de la Revista Virtual del CIR, y por la iniciativa Go-RAD, actividades asociadas al Colegio Interamericano de Radiología y la International Society of Radiology, respectivamente.

Esto ha repercutido en que en los últimos años hemos tenido un aumento creciente de las visitas por vía electrónica a nuestra Revista, aumentando de 555.652 visitas en 2012, a 908.595 en 2013 , y a mediados de noviembre 2014 alcanzamos los 1.264 .158 visitas. Esto refleja un incremento de un $227 \%$ en los últimos años.

Hoy cerramos el vigésimo volumen de Revista Chilena de Radiología, y se hace muy necesario reconocer la enorme labor cumplida por muchos radiólogos que de forma desinteresada y absolutamente ad-honorem, han permitido el crecimiento continuo de nuestra revista. Hemos sido destacados en la esfera radiológica internacional, por nuestra continuidad y progreso en la calidad de los artículos aquí publicado, lo que se refleja en nuestra constante inclusión en instancias de difusión del conocimiento.

Cada Editor y los miembros de los sucesivos Comités Editoriales han puesto su mayor esfuerzo para lograr esta meta. La siguiente meta es más ambiciosa y es optar a la indexación en Pubmed. Esta vitrina del conocimiento es una forma de poder dar la mayor difusión a la labor que se realiza en nuestras instituciones académicas, a la comunidad radiológica y médica internacional.

A eso hay que orientar los esfuerzos, estos últimos años se ha trabajado en mejorar la calidad metodológica y el número de trabajos originales, sin descuidar las necesarias contribuciones en artículos de revisión y educación continua. Hemos abierto canales y secciones para la publicación de radiólogos jóvenes o residentes, y damos difusión a los trabajos premiados en los Congresos Chilenos de Radiología.

En este número queremos rendir un homenaje a todos aquellos que han permitido que la Revista Chilena de Radiología haya surgido como un referente de la radiología nacional e iberoamericana. 


\section{Editores Revista Chilena Radiología}

Dr. Pablo Soffia Sánchez (Años 1995, 1998)

Dr. Guillermo Ríos Olsen (Años 1996 - 1997)

Dr. Marcelo Castro Salas (Años 1999 - 2000)

Dr. José Domingo Arce Valenzuela (Años 2001 - 2006)

Dra. Karla Moënne Bühlmann (Años 2006 - 2010)

Dr. Claudio Silva Fuente-Alba (Años 2010 - 2014)

\section{Miembros del Comité Editorial}

Dra. Bernardita Aguirre Donoso (1999 - 2000)

Dr. José Domingo Arce Valenzuela (1997 - 2001, Editor 2001 - 2006)

Dr. Enrique Bosch Ostalé (1995 - 1996, 2006 - 2008)

Dr. Marcelo Castro Salas (1998, Editor 1999-2000)

Dr. Vinicio Cervilla Oltremari (1995 - 1996)

Dr. Claudio Cortés Arriagada (2001 - 2014)

Dr. Gonzalo Delgado Pereda (2003 - 2006)

Dra. Consuelo Fernández Tello (1997)

Dr. Santiago Gallardo Pizarro QEPD (1997 - 1998)

Dr. Marcelo Gálvez Moya ( 2006 - 2014)

Dr. Cristián García Bruce (1995 - 1996)

Dr. Andrea Glasinovic Pizarro (1997)

Dr. Isidro Huete Lira (1997 - 1998, 2001 - 2009)

Dr. Cristián Larraín Garcés (1996)

Dr. César Lovera Fernández (1999 - 2000)

Dra. Teresa Massardo Vega (2001 - 2006)

Dr. Andrés O'Brien Solar (2006 - 2014)

Dra. Pilar Orellana Briones (1995 - 1998)

Dra. Dulia Ortega Torres (1997)

Dra. Dravna Razmilic Valdés (1998)

Dr. Giancarlo Schiappacasse Faundes (2008 - 2014)

Dr. Claudio Silva Fuente-Alba (2006 - 2009, Editor 2009-2014)

Dr. Pablo Soffia Sánchez (1999 - 2000)

Dr. Cristián Varela Ubilla ( 2001 - 2002)

Dr. Marco Verdugo Podlech (1997 - 2000)

Sr. Mauricio Vergara Edwards (2000 - 2007)

Dra. Carolina Whittle Pinto (1998 - 2006)

Dr. Cristián Willenmann Espínola (1997)

Los invito a seguir participando y apoyando a Revista Chilena de Radiología, la cual es la vía de expresión directa de la actividad científica, gremial y docente de la Sociedad Chilena de Radiología.

Bibliografía:

1. Medina FJ. 10 años. Rev Chil Radiol 2004; 10 (1): 4

Silva C. Labor Editorial en Revista Chilena de Radiología vigésimo volumen y proyección al futuro. Rev Chil Radiol 2014: 20(4); 168-169.

Correspondencia: Claudio Silva F-A / drsilvafa@gmail.com 